\title{
Fundraising, celebrations and classroom rewards are substantial sources of unhealthy foods and beverages on public school campuses
}

\author{
Susan L Caparosa', Maggie Shordon ${ }^{1}$, Asherlev T Santos², Magdalena E \\ Pomichowski ${ }^{1}$, David A Dzewaltowski ${ }^{3}$ and Karen J Coleman ${ }^{1, *}$ \\ 'Department of Research and Evaluation, Kaiser Permanente Southern California, Southern California \\ Permanente Medical Group, 100 S. Los Robles, 2nd Floor, Pasadena, CA 91101 , USA: ${ }^{2}$ Graduate School of \\ Public Health Joint Doctoral Program, San Diego State University and University of California at San Diego, \\ San Diego, CA, USA: ${ }^{3}$ Department of Kinesiology, Kansas State University, Manhatten, KS, USA
}

Submitted 20 August 2012: Final revision received 15 April 2013: Accepted 17 April 2013: First published online 14 June 2013

\begin{abstract}
Objective: The emphasis in school nutrition policy has been on vending and competitive items. Our study was designed to characterize and quantify the amount and source of other foods and beverages on school campuses.

Design: A cross-sectional observational study was conducted using a specially designed objective nutrition observation system.

Setting: One low-income school district in southern California with six elementary and two middle schools.

Subjects: Data were not collected from individual children. A total of 4033 students, $42 \%$ of whom were Hispanic/Latino, $26 \%$ African American and $21 \%$ non-Hispanic white, were observed across school settings.

Results: Data were collected continuously from 9 January 2008 to 16 June 2010. Healthy foods had, per serving, total energy $\leq 732 \mathrm{~kJ}$ ( $\leq 175 \mathrm{kcal}$ ), total fat content $\leq 35 \%$, total saturated fat $\leq 10 \%$, sugar less $\leq 15$ g, sodium $<200 \mathrm{mg}$ and trans-fat $\leq 0.5 \mathrm{~g}$. Healthy beverages were only $100 \%$ juice or water, and unflavoured non-fat, $1 \%, 2 \%$ milk and soya or rice milk. The system had high inter-rater reliability $(r=0.78$ to 0.99$)$, percentage agreement ( $83 \%$ to $100 \%)$ and test-retest reliability $(r=0.81$ to $0 \cdot 98)$. Significantly more unhealthy foods and beverages than healthy items were observed on all campuses $(P<0 \cdot 001)$. An average of $1 \cdot 26(\mathrm{SD} 0 \cdot 46)$ items per student per week was found with an average of 0.86 (SD 0.34 ) unhealthy items per child per week.

Conclusions: There were substantial amounts of unhealthy foods and beverages brought onto campuses for classroom rewards, celebrations and fundraising that should be targeted for intervention.
\end{abstract}

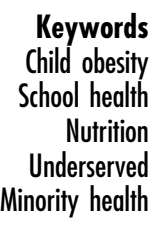

Over the past 30 years, the prevalence of overweight and obesity has increased sharply for US children and adolescents with as many as $24 \%$ of ethnic minority adolescents now considered obese ${ }^{(1)}$. Schools are an ideal setting for promoting, engaging in and modelling life-long healthful eating and physical activity behaviours that could lead to prevention of obesity and diabetes in children and their families ${ }^{(2,3)}$. Prevention and treatment recommendations for child obesity have emphasized the importance of changing obesogenic policies and environments, especially in settings where children spend most of their time such as schools ${ }^{(3,4)}$.

The majority of the work done to change nutrition environments in school settings has focused on the quality of school meals and/or reducing unhealthy competitive foods sold on campuses ${ }^{(5-11)}$. These studies relied heavily on self-report surveys to assess the school nutrition environment. Given that schools have direct pressure to reduce unhealthy foods and beverages on their campuses through the federally mandated wellness policy requirement, self-report is likely to lead to underestimation of these items. Direct observation by non-school staff may provide more accurate assessments of outside foods and beverages on campus.

To date, direct observation has been used to catalogue foods and beverages consumed during school meals ${ }^{(6-10,12)}$, competitive foods offered off campus ${ }^{(11)}$ and general vending contents ${ }^{(5)}$. Although school meals and competitive items sold on and off campus are important components of the school nutrition environment, there are also foods and 
beverages brought on campus by children from home and by teachers and other school staff. There have been only a few studies that have used behavioural observation to assess foods and beverages brought on campus from home, and these have all focused on what children bring to school for lunch ${ }^{(13-16)}$.

To address the other environments in schools such as classrooms and playgrounds, we developed a unique observation system to quantify and categorize all foods and beverages on public elementary- and middle-school campuses as part of a school nutrition environment intervention called Healthy Options for Nutrition Environments in Schools (Healthy ONES) ${ }^{(17)}$. The present study describes the results of these observations for the baseline phase of Healthy ONES.

\section{Methods}

\section{Settings and participants}

Because the present study was a part of the Healthy ONES intervention study, we were limited to observing all schools in a single school district. All schools in the district chose to participate in the study. The school district was low income (100\% of children on free and reduced-price meals and over $80 \%$ were economically disadvantaged) and contained only six elementary (grades $\mathrm{K}-5$; ages 5-11 years old) and two middle schools (grades 6-8; ages 12-14 years old). There were a total of 4033 students, $42 \%$ of whom were Hispanic/Latino, 26\% African American and 21\% nonHispanic white. There were no high schools and there was no vending available to children on any school campus. Nutrition services sold competitive foods and beverages during school lunches at middle schools only. No other sales of competitive foods and beverages were allowed.

The targets of the observational system were food and beverage items brought to schools from off campus. Data were never collected from individual children, thus informed consent was not necessary. Institutional review board approval for the study was obtained from San Diego State University and Kaiser Permanente Southern California.

\section{Observational system}

The research team spent the autumn semester of the baseline year of Healthy ONES mapping each school's campus, distinguishing discrete environments in which foods and beverages were consumed. These environments were classrooms, playgrounds/recess areas and cafeterias/gyms. All observation methods were based upon the basic principles of behavioural observation ${ }^{(18)}$. Examples of these principles are that the behaviour is observable, can be easily operationalized without ambiguity for data collection and can be reliably recorded by different observers. Detailed protocols and data collection instruments are available upon request. Data were collected continuously from 9 January 2008 to 16 June 2010.

\section{Classrooms}

Because we were not allowed to directly observe classrooms, we had to develop a less traditional method of observation for this environment. To catalogue outside foods and beverages in classrooms we 'observed' their trash. Classroom trash on these campuses was emptied into large garbage receptacles by teachers throughout the school day. These receptacles were housed outside and served two or three classrooms (all campuses had classroom entrances facing outdoor areas). This was done so that custodial staff did not disturb classroom activities. These receptacles were emptied once by custodial staff at the end of each school day.

Classroom trash at each school was catalogued at the end of each month throughout the school year with additional observations for holidays and school-wide events. In the first year of the project there were $12 \mathrm{~d}$ observed (2007/08), and $15 \mathrm{~d}$ each in years $2(2008 / 09)$ and $3(2009 / 10)$. The order in which schools were observed during each month was randomized, as was the choice of where on campus we began observations. Trash observations generally reflected physical evidence of what had occurred during school hours that day and for some of the previous day. Whenever possible, observations were made for all trash cans outside classrooms.

Observations were made in pairs. One observer retrieved items out of trash containers and set them on a collection tray while the second observer completed the data collection form. The following information was recorded for every item: brand, item description, size, if it was from nutrition services and the number of items. Once all items were recorded, the trash was returned to the container. Trash containers in school corridors were observed from left to right facing the containers. An effort was made to retrieve all food and beverage containers and wrappers, and fruit skins and cores, in each trash container; however, if the container was full, then items were retrieved for only the top $50 \%$ of the content. Special care was taken to conduct observations in a safe, sanitary manner. All observers wore gloves, carried sanitary wipes, tied back hair, and did not observe trash bins or bags that appeared to have unsanitary/ hazardous materials such as diapers and glass or to contain excessive liquids.

Observations were made at the end of the school day before trash cans were emptied by custodial staff. Occasionally, all trash containers were emptied by custodial staff before we were able to observe. In this case, observations were made at the campus dumpsters by randomly selecting eight trash bags that did not contain lunch trash and emptying the contents for observation. Lunch trash was easily distinguished from other trash sources because it was much heavier and contained milk containers.

\section{Playgrounds/recess}

This environment existed only in elementary schools as morning recess. For all schools, afternoon recess was paired with school lunch and was observed as part 

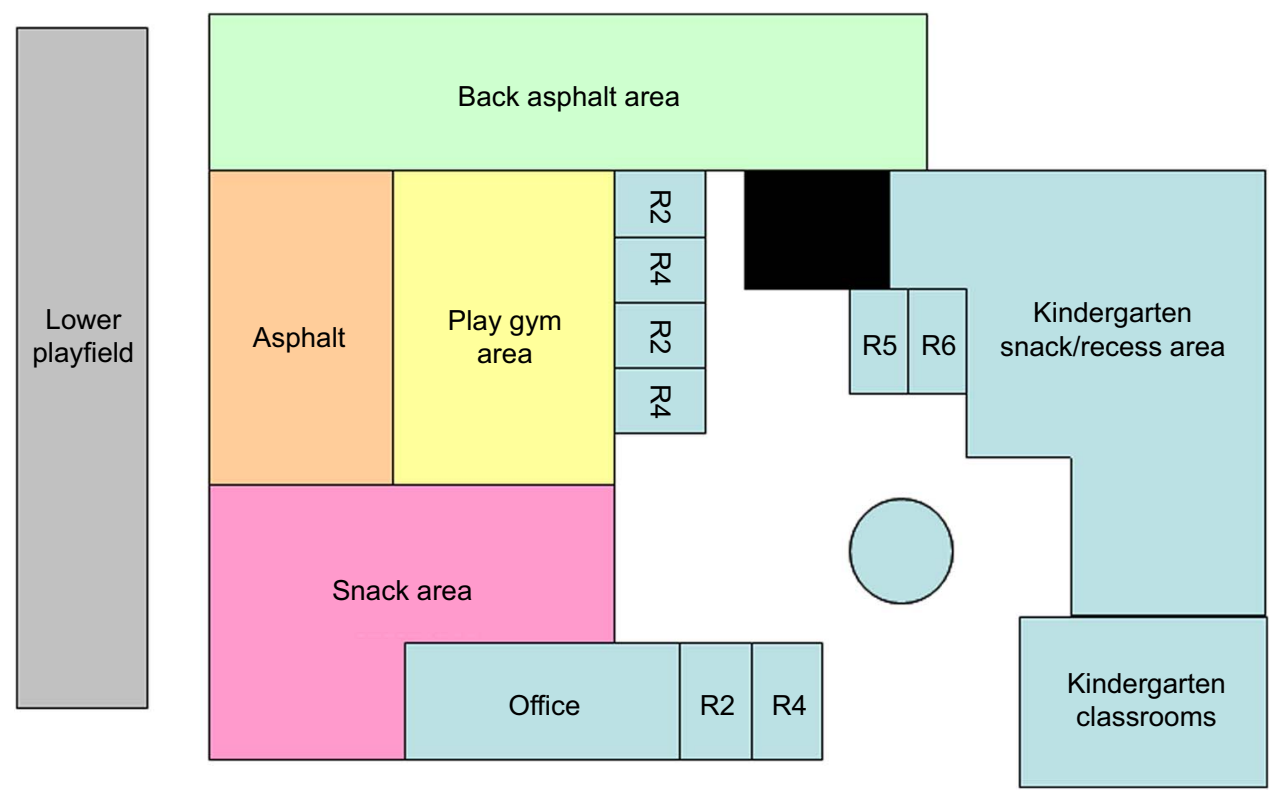

Fig. 1 Example campus map for behavioural observation. Each colour is an observational sector

of the cafeteria/gym environment (see next section). We observed the playground/recess environment on the same days we collected classroom trash data. Because we were able to directly observe activity in the playground/ recess areas, more traditional methods of behavioural observation were used by adapting the methods used to observe physical activity ${ }^{(19)}$.

The system was implemented by creating observation sectors within the morning recess area (see Fig. 1 as an example - sectors are shown as different colours) and observations were made by sector during the recess period. A sector was an easily observed area that could be scanned from one location and did not contain so much activity that it was difficult to collect data reliably. Sectors were often indicated by physical barriers such as walls, indoor $v$. outdoor settings and physical differences such as grass $v$. asphalt. An observation session began with a scan of each sector recording all food and beverage items that could be seen in each sector and then moving to the next sector mapped in the recess area. The second scan was done to count all the children in each sector. Subsequent scans were made to record foods and beverages not recorded with the first scan. Data recorded were item description, brand and number. Serving size was not recorded (as was done with trash items) because observers could not examine items closely. We also made additional notes about whether an item was a stand-alone snack or part of a child's bag/box lunch. Scans began when at least $50 \%$ of all children entered the playground/recess area and continued until $50 \%$ of all children left the area or no new items were noted.

\section{Cafeterias/gyms}

The cafeteria/gym area was the site at which we observed school lunch and afternoon recess. Observations were made for at least four separate days in each semester in different weeks, approximately once per month for every school. Schools had half-days during the week and those days were not chosen for observation (i.e. Wednesdays were half days in many schools and were not chosen for lunch observations). Attempts were made to observe different days during the week once per semester (one Monday, Tuesday, Thursday and Friday). The week observed during the month was randomly chosen. The observation period began by arriving before the first lunch period and noting all foods and beverages offered by food services. This was done before children began entering the area so that we could distinguish these items from those brought by children from home. During the day chosen, all lunch services (children were fed in groups by grade) were observed and observation periods began and ended with each lunch service.

The same method was used to observe outside foods and beverages as that described for morning recess except that environmental scans began by walking up and down aisles of seated children starting from the ones nearest the cash register, moving up the aisle and then down the opposite aisle, etc., until all tables had been scanned. Scans began when at least $50 \%$ of all children for a certain lunch service were seated. Scans continued until $50 \%$ of all children left the lunch area or no new items were noted.

For the schools we observed, all food and beverage items were consumed in the cafeteria/gym area and not on the playground where children went for afternoon recess following lunch. However, if children had been consuming foods and beverages on the playground during this time, we would have continued the environmental scans until $50 \%$ of all children left the playground/recess area. 


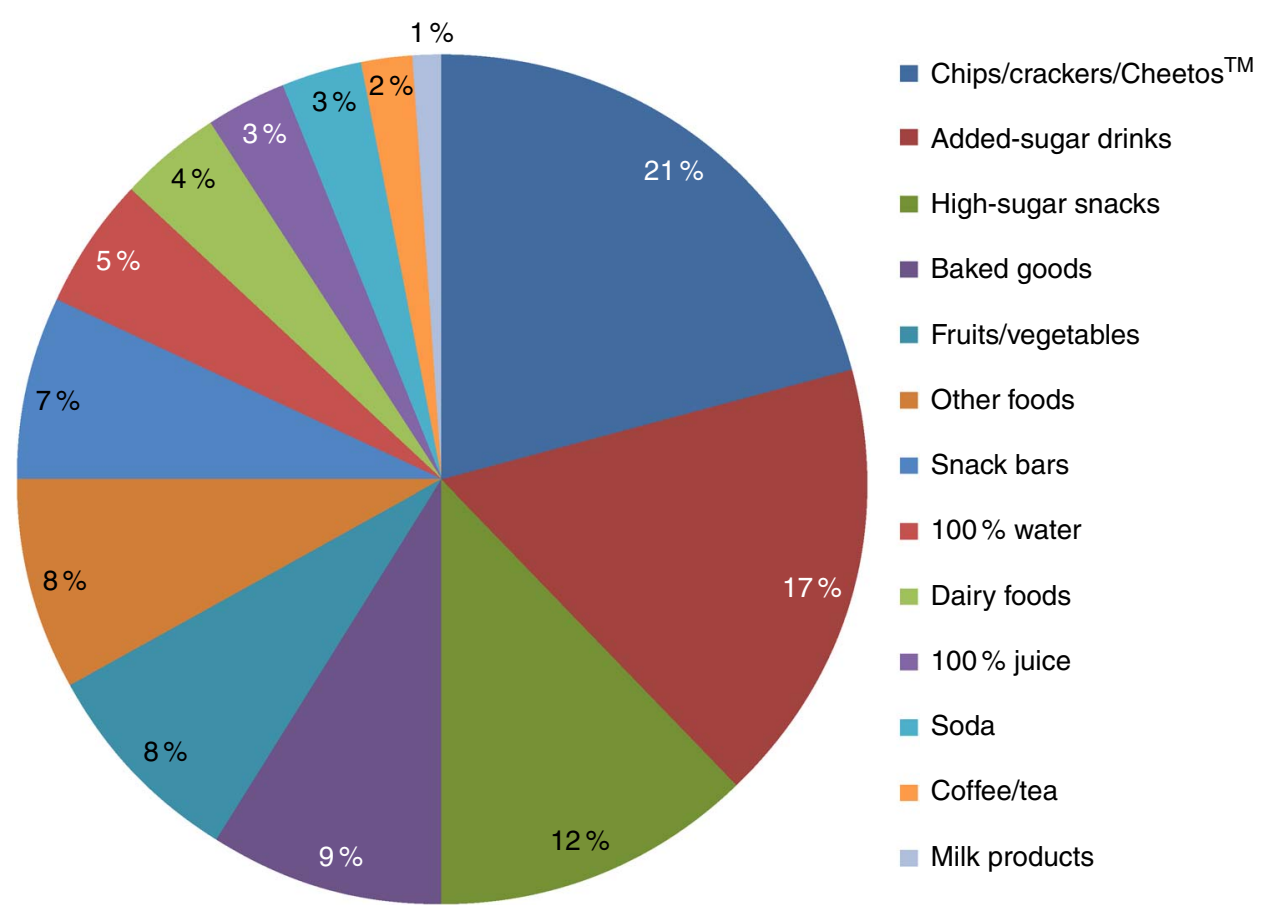

Fig. 2 Distribution of observed foods and beverages across all school campuses; six elementary and two middle schools from one low-income school district in southern California, USA, 2008-2010 (baseline phase of Healthy ONES school nutrition environment intervention)

\section{Training and inter-rater reliability}

After development and testing of the observation methods, training and reliability were conducted. Training consisted of the last author and all observers conducting observations and discussing all findings as observations were being made. Adjustments were made to the protocol when procedures were not clear. Following training, observers went to one elementary school and one middle school in pairs, collected data independently and then brought back all sets of data to calculate reliability. Each time a new observer was added to the research team, he/she underwent the same training and reliability procedure.

\section{Food and beverage categorization}

General food and beverage groupings

There were literally hundreds of food and beverage items recorded which presented a challenge for data analyses. To consolidate data for analyses, thirteen food and beverage categories were created based upon general commercial product groups, common ingredients and public health efforts to promote healthy eating (see Fig. 2 for a distribution of these items across schools). The beverage categories were: (i) $100 \%$ water; (ii) $100 \%$ juice; (iii) milk products; (iv) added sugar (fruit-flavoured drinks, energy drinks, sports drinks, flavoured water); (v) soda (both diet and regular); and (vi) coffee/tea. The food categories were: (i) chips/crackers/ Cheetos $^{\mathrm{TM}}$; (ii) high-sugar snacks (candy, fruit-flavoured snacks, frozen treats); (iii) baked goods (cookies, brownies, muffins); (iv) $100 \%$ fruits and vegetables including 100\% fruit products; (v) snack bars (granola, energy, cereal); (vi) dairy (yoghurt, cheese, other dairy foods); and (vii) other (prepared meals, fast food, nuts, pudding, popcorn, cereal, cold cuts). To use this observation system in other regions of the country, these categories could be altered depending upon the school system being observed.

\section{Healthy v. unhealthy classifications}

The Healthy ONES intervention targeted foods and beverages that were considered unhealthy by a number of leading agencies in children's nutrition ${ }^{(20-22)}$. Thus for future intervention purposes we created four very broad categories: (i) unhealthy foods; (ii) unhealthy beverages; (iii) healthy foods; and (iv) healthy beverages. The standards used to classify healthy and unhealthy items were adapted from the following recommendations: nutrition standards for foods and beverages offered in competition with federally reimbursable meals by the California Senate Bill $12^{(20)}$, the US Department of Agriculture's HealthierUS School Challenge (HUSSC) ${ }^{(21)}$; and the Institute of Medicine guidelines ${ }^{(22)}$.

A healthy food had to have all of the following characteristics: total energy $\leq 732 \mathrm{~kJ}$ ( $\leq 175 \mathrm{kcal}$ ), fat content $\leq 35 \%$ of total energy, saturated fat content $\leq 10 \%$ of total energy, sugar $\leq 15 \mathrm{~g}$, sodium $<200 \mathrm{mg}$ and trans-fat $\leq 0.5 \mathrm{~g}$. Only $100 \%$ juice or water, and unflavoured non-fat, $1 \%$, $2 \%$ milk and soya or rice milk were considered healthy beverages. Individual food and beverage items were combined into these categories independent of the categories created for the thirteen general groupings. 


\section{Analyses}

The unit of analysis for all data presentation was the school, not the individual child. Raw data are item counts per school in any given environment. The total sample size for comparisons across environments and types of food and beverages was $n$ 8. Inter-rater and test-retest reliability were calculated using Pearson product-moment correlations for total item counts. All other inter-rater reliability calculations used percentage agreement because the data were categorical. Inter-rater reliability was calculated on samples of baseline observation data from the spring semester. Test-retest reliability was calculated using total item counts from control schools ( $n$ 4) for autumn and spring semesters of the first and second intervention years.

Descriptive statistics were used to present the results of baseline outside food and beverage observation findings across all observation settings. Although data were collected as total item counts per observation, to compare campuses with each other or to examine changes over time these counts had to be corrected for the size of each school. Larger schools had greater amounts of foods and beverages simply because they had more students and staff. Thus to standardize the data for comparison between schools or across time we calculated total item counts per child. This was calculated by obtaining the student attendance for the day of observation for classroom observations or counting the children in the cafeteria/gym or playground/recess areas when conducting each observation in these two environments and dividing the total items observed for that day by these counts of children. Finally, we used this statistic and multiplied it by 5 to determine total items per child per week so that we could estimate child intake of unhealthy foods and beverages throughout the school year.

ANOVA was used to determine differences between environments/activities (classroom, playground/recess, cafeteria/gym) for overall total items per child per week and unhealthy/healthy food and beverage items per child per week. Significant differences between environments were presented at $P \leq 0 \cdot 01$ to control for type I error. The Tukey's post hoc statistic was used to determine which environments were different if the omnibus $F$ test was significant.

\section{Results}

\section{Instrument reliability and validity}

Across observation tools, inter-rater reliability for total number of items recorded per observation ranged from $r=0.78$ to $r=0.99$. Percentage agreement for brand name and type of food/beverage ranged from $83 \%$ to $100 \%$. Item size was recorded only for classroom trash and percentage agreement was 93\%. Test-retest reliability for the total number of observed items in control schools for the autumn semester was $r=0.86$ for the classroom, $r=0.90$ for playground/recess and $r=0.90$ for the cafeteria/gym. In the spring semester test-retest reliability was $r=0.81$ for the classroom, $r=0.90$ for the recess/playground and $r=0.98$ for the cafeteria/gym. Percentage agreement between raters for consolidating foods and beverages into the thirteen general categories shown in Fig. 2 was 95\%, ranging from $85 \%$ to $100 \%$. Percentage agreement between raters for the creation of healthy and unhealthy categories was $96 \%$ for unhealthy foods, $100 \%$ for unhealthy beverages, $100 \%$ for healthy foods and $100 \%$ for healthy beverages.

\section{General food and beverage groupings}

A total of 9601 food and beverage items were catalogued (7970 for elementary schools and 1631 for middle schools). Figure 2 presents the distribution of outside food and beverage groupings across all schools. There were 3017 outside beverage items (31\% of all items) observed and 6584 (69\% of all items) outside food items. The most frequently observed items were high-sugar snacks (12\%) and sugar-added beverages (17\%) followed by chips/crackers/Cheetos ${ }^{\mathrm{TM}}$ (21\%), accounting for half of all items observed. This is in contrast to traditionally 'healthy' foods and beverages like fruits, vegetables and $100 \%$ water, at $14 \%$ of all items observed.

Table 1 presents the general food and beverage in each environment for all schools. The average number of items per child per week across all environments and food and beverage categories was $1 \cdot 26$ (SD 0 46). Across all food and beverage categories, there were no significant differences among school environments. However, when different categories were examined, there were significant differences among environments. These were found for added-sugar beverages $(F(2,21)=9 \cdot 45 ; P=0 \cdot 001)$, coffee/ tea $(F(2,21)=10 \cdot 09 ; \quad P=0 \cdot 001)$, fruits and vegetables $(F(2,21)=10 \cdot 29 ; P=0 \cdot 001)$ and crackers $/$ chips $/$ Cheetos ${ }^{\mathrm{TM}}$ $(F(2,21)=6 \cdot 41 ; P=0 \cdot 007)$.

There were fewer added-sugar drinks per child per week in classrooms when compared with both playground/recess $(P=0 \cdot 02)$ and cafeteria/gym $(P=0 \cdot 001)$ environments; while there was more coffee/tea in classrooms when compared with playground/recess $(P=0 \cdot 048)$ and cafeteria/gym $(P=0.001)$. For both types of beverages, playground/recess and cafeteria/gym environments were not different. There were more fruit and vegetable $(P=0.001$ classroom; $P=0.007$ cafeteria/gym) and $\quad$ crackers/chips/Cheetos ${ }^{\mathrm{TM}} \quad(P=0.02 \quad$ classroom; $P=0.01$ cafeteria/gym) items per child per week in playground/recess than in either the classroom or the cafeteria/gym lunch environment.

\section{Healtby v. unbealthy classifications}

There were significantly more unhealthy drinks than healthy drinks on campuses $(t(21)=-8 \cdot 41 ; P<0 \cdot 001)$ as well as more unhealthy foods than healthy foods on 
Table 1 Outside food and beverage items across all campuses for each observed environment; six elementary and two middle schools from one low-income school district in southern California, USA, 2008-2010 (baseline phase of Healthy ONES school nutrition environment intervention)

\begin{tabular}{|c|c|c|c|c|c|c|c|c|}
\hline \multirow[b]{2}{*}{ Item category } & \multicolumn{2}{|c|}{ Playgrounds/recess } & \multicolumn{2}{|c|}{ Classrooms } & \multicolumn{2}{|c|}{ Cafeterias/gyms } & \multicolumn{2}{|c|}{ All } \\
\hline & Mean & SD & Mean & SD & Mean & SD & Mean & SD \\
\hline \multicolumn{9}{|l|}{ Beverages } \\
\hline Added sugar* & $0 \cdot 30^{\mathrm{a}}$ & $0 \cdot 13$ & $0 \cdot 15$ & 0.08 & $0.34^{\mathrm{a}}$ & 0.07 & $0 \cdot 26$ & $0 \cdot 12$ \\
\hline $100 \%$ water & 0.05 & 0.03 & 0.06 & 0.05 & 0.09 & 0.04 & 0.07 & 0.04 \\
\hline $100 \%$ juice & $0 \cdot 01$ & $0 \cdot 01$ & 0.04 & 0.04 & 0.03 & 0.03 & 0.03 & 0.03 \\
\hline Milk & 0.004 & 0.004 & 0.01 & 0.02 & 0.003 & 0.005 & 0.01 & $0 \cdot 01$ \\
\hline Soda & $0 \cdot 01$ & 0.01 & 0.05 & 0.07 & 0.03 & 0.05 & 0.03 & 0.05 \\
\hline Coffee/tea* & $0.02^{b}$ & 0.01 & 0.04 & 0.02 & $0 \cdot 01^{b}$ & 0.01 & 0.02 & 0.02 \\
\hline \multicolumn{9}{|l|}{ Foods } \\
\hline Chips/crackers/Cheetos ${ }^{\mathrm{TM}}{ }$ & 0.44 & $0 \cdot 20$ & $0 \cdot 22^{c}$ & $0 \cdot 12$ & $0 \cdot 21^{c}$ & 0.09 & 0.27 & $0 \cdot 17$ \\
\hline High-sugar snacks & $0 \cdot 12$ & 0.06 & $0 \cdot 17$ & 0.08 & 0.07 & 0.05 & $0 \cdot 12$ & 0.07 \\
\hline Fruits/vegetables* & $0 \cdot 19$ & 0.06 & $0.08^{\mathrm{c}}$ & 0.04 & $0 \cdot 10^{c}$ & 0.05 & $0 \cdot 12$ & 0.07 \\
\hline Snack bars & 0.09 & 0.03 & $0 \cdot 10$ & 0.06 & 0.04 & 0.02 & 0.08 & 0.05 \\
\hline Baked goods & 0.08 & 0.07 & 0.06 & 0.05 & 0.02 & 0.02 & 0.05 & 0.05 \\
\hline Dairy & 0.07 & 0.03 & 0.04 & 0.03 & 0.04 & 0.02 & 0.05 & 0.03 \\
\hline Other & $0 \cdot 13$ & 0.06 & 0.08 & 0.04 & $0 \cdot 11$ & 0.04 & $0 \cdot 10$ & 0.05 \\
\hline \multicolumn{9}{|l|}{ Unhealthy items } \\
\hline Beverages* ${ }^{*}$ & $0 \cdot 30$ & $0 \cdot 13$ & $0 \cdot 20$ & 0.09 & $0 \cdot 37^{d}$ & 0.08 & 0.29 & $0 \cdot 12$ \\
\hline Foods* & $0.83^{e}$ & 0.34 & 0.55 & 0.22 & $0 \cdot 41$ & $0 \cdot 15$ & 0.57 & 0.28 \\
\hline \multicolumn{9}{|l|}{ Healthy items } \\
\hline Beverages & 0.07 & 0.04 & $0 \cdot 12$ & 0.09 & $0 \cdot 12$ & 0.05 & $0 \cdot 11$ & 0.06 \\
\hline Foods* & $0.33^{f}$ & $0 \cdot 10$ & 0.21 & $0 \cdot 11$ & $0 \cdot 18$ & 0.06 & 0.23 & $0 \cdot 11$ \\
\hline
\end{tabular}

Healthy ONES, Healthy Options for Nutrition Environments in Schools.

*Mean values were significantly different between environments $(P=0.001)$.

a Mean value was significantly higher than that for classrooms $(P<0.05)$.

${ }^{b}$ Mean value was significantly lower than that for classrooms $(P<0.05)$.

${ }^{\mathrm{C}}$ Mean value was significantly lower than that for playgrounds/recess $(P<0.05)$.

${ }^{\mathrm{d}}$ Mean value was significantly higher than that for classrooms $(P=0.007)$.

${ }^{\mathrm{e}}$ Mean value was significantly higher than that for cafeterias/gyms $(P=0.01)$

${ }^{f} \mathrm{Mean}$ value was significantly higher than that for cafeterias/gyms $(P=0.01)$.

campuses $(t(21)=-7 \cdot 34 ; \quad P<0 \cdot 001)$, regardless of school environment. Table 1 also presents the findings for healthy and unhealthy foods and beverages across school environments. The amount of healthy foods per child per week differed for school environments $(F(2,21)=5 \cdot 47$; $P=0 \cdot 01)$ such that more healthy foods were found in playground/recess when compared with cafeteria/gym $(P=0 \cdot 01)$ while the other environments did not differ. Healthy drinks did not differ across environments. Unhealthy drinks per child per week varied by school environment $(F(2,21)=6 \cdot 04 ; P 0 \cdot 01)$ such that there were more in cafeteria/gym than in the classroom $(P=0 \cdot 007)$ with no other environment differences. Finally, total unhealthy foods per child per week also varied by school environment $(F(2,21)=5 \cdot 40 ; P=0 \cdot 01)$ with playground/ recess having more of these foods than the cafeteria/gym $(P=0 \cdot 01)$ with no other significant differences between environments.

\section{Discussion}

We present here observational findings for the overall nutrition environment in public schools that assesses other sources of foods and beverages not addressed in the existing school health literature, including foods and beverages brought from home by teachers and other school staff, students and parents. We observed 7970 outside food and beverage items for a school district with 4033 students in one semester alone, the majority of which were considered unhealthy by a number of leading agencies in children's nutrition ${ }^{(2-22)}$. When unhealthy foods and beverages were combined, we observed an average of $0 \cdot 86$ (SD 0.34) unhealthy items per child per week.

It is difficult to compare our findings with those in the literature because the data to date have been focused on quantifying sources of competitive vending and food sales on campuses and not foods from other sources. Data from the SNDA-III study, a cross-sectional study that included a national sample of public school districts, schools and children in the 2004-2005 school year, reported desserts and low-nutrient/energy-dense snacks (53\%), candy (18\%), chips, popcorn, crackers and pretzels (22\%), and beverages other than milk and $100 \%$ juice (46\%), as the most common competitive foods and beverages consumed $^{(23)}$. In elementary schools, the most commonly reported areas where there were outside foods were school activities, classroom parties, fundraisers and treats from teachers and school staff. Vending machines were the most common source for outside foods and beverages in middle and high schools. These findings are similar to what we found in our observations.

There have been several efforts to ban or restrict vending to healthy items in public schools as well as 
eliminate or limit competitive food and beverage sales on campuses ${ }^{(5-12)}$. Based upon our findings, restricting vending or competitive food and beverage sales is unlikely to make a significant impact on the consumption of unhealthy foods and beverages during school hours. The school district in which we worked did not have vending nor did it have competitive food and beverage sales on elementary-school campuses, yet consumption of unhealthy foods and beverages was widespread.

Our study also found that playground/recess and classroom environments generally had more food items from outside sources than the lunch environment. Thus, focusing primarily on lunch periods for study and intervention as the literature has done to date ${ }^{(13-16)}$ may miss opportunities for impacting the school nutrition environment as a whole. The US Department of Agriculture is beginning to address this issue and promote more comprehensive guidelines for nutrition across school campuses through the HUSSC. This is a voluntary certification initiative established in 2004 that recognizes schools participating in the National School Lunch Program that have created healthier school environments through nutrition and physical activity ${ }^{(21)}$.

The guidelines for this initiative are comprehensive and unambiguous; however, these recommendations for competitive foods and beverages have not been legislated at the federal level and the impact of the HUSSC initiative is unknown. In general, there has been high levels of policy implementation for school meal programmes (92\%) and à la carte items (72\%), but implementation of nutrition standards for fundraising, classroom parties and school stores has been low $(33 \%)^{(24)}$. Our data support this finding, as outside foods and beverages on the observed campuses were from parents, staff and children for the purposes of celebrations, snacking and fundraising.

Two groups have been doing similar work in other settings. The Nutrition and Physical Activity Self-Assessment for Child Care (NAP SACC) intervention ${ }^{(25-27)}$ developed the Environment and Policy Assessment \& Observation (EPAO) to assess food and beverages served, staff-child meal interactions, staff support for nutrition and how children are fed in child-care settings. The Nutrition Environment Measurement Study (NEMS) developed two systems of observation to quantify and describe the quality of foods offered by restaurants and stores ${ }^{(28,29)}$. The NEMS developed a food environment score based on availability, quality and price. However, our work is the first to objectively describe the foods and beverages across a variety of public school environments.

There are a number of limitations with the current study that should be considered. We were limited in our opportunity to observe all foods and beverages on campuses for a variety of reasons. During lunch we may have missed items as we excluded lunch trash from data collection and had to rely on direct observation of children in this environment. This was also the case for playground/ recess, although most of the trash from this environment was included in the classroom observations. It is likely that we underestimated the presence of vegetables and other foods without containers, wrappers, skins or peels. There is also a possibility that we overestimated foods and beverages because items from playground/recess and cafeteria/gym areas could have been counted again when thrown out in classroom trash. It is likely that this effect was minimal because there were more chances to miss items than double count them.

Another limitation was that sorting through trash may not be an acceptable method of data collection for all research projects. To ensure the safety of the research staff collecting data, we were very careful to use sanitary techniques and no trash was sorted that appeared at all hazardous. Finally, our results should not be generalized to other school campuses in other parts of the country. Each school campus has a unique set of environments with different foods and beverages. We present this method of observations for other research that can begin to study these environments and truly quantify the sources of foods and beverages on public school campuses.

Outside foods and beverages on campuses are part of the general trend seen for increased snacking behaviour throughout the USA ${ }^{(30)}$, which has coincided with the increase seen in child obesity. However, the relationship between snacking and body weight is not clear. Most reports have found that snacking frequency did not increase body weight in US children ${ }^{(31-34)}$. In contrast, a 4-year longitudinal study by Francis et $a l .{ }^{(35)}$ reported snacking as a risk factor for the development of overweight in 173 non-Hispanic white girls. More research is needed to characterize and quantify the amount and source of unhealthy foods and beverages on campuses other than vending, competitive food sales and school meals, and to understand the role of these snacks in childhood obesity. Future interventions that target the substantial amount of unhealthy foods brought onto campus in elementary schools for recess snacks, classroom parties and school-wide events need to be evaluated. Our findings from Healthy ONES demonstrated that it is possible to substantially reduce unhealthy foods and beverages in public schools by using a participatory public health approach to environmental and policy change ${ }^{(17)}$. Although regulating food and beverage items brought onto campus is a burdensome and time-intensive task, it provides numerous opportunities to engage and educate parents about nutrition while improving what is available during the school day and possibly influencing what is purchased and consumed at home.

\section{Acknowledgements}

Sources of funding: This study was provided by the US Department of Agriculture National Research Initiative (NRI) 
award \#2007-55215-05323/(2007-55215-18241). Conflicts of interest: None of the authors have any conflicts of interest to declare. Authors' contributions: S.L.C. wrote the paper and also participated in designing and conducting the research study. M.S. coordinated and conducted the research study and also participated in its design. She also assisted with the writing of the manuscript. A.T.S. participated in the design and conducted the research study. He also assisted with the writing of the manuscript. M.E.P. participated in the design and conducted the research study. He also assisted with the writing of the manuscript. D.A.D. participated in the design of the research study. He also assisted with the writing of the manuscript and interpretation of the findings. K.J.C. was the principal investigator of the study and as such designed, conducted and had primary responsibility for the study and final content of the manuscript. She also contributed to the writing of the manuscript and conducted the statistical analyses. Acknowledgements: The authors would like to thank the staff, students, teachers and parents at the Lemon Grove School District for their input to the study outcomes. They would like to especially acknowledge the contributions of Robin McNulty, Nutrition Services Director and Ernest Anastos, Superintendent.

\section{References}

1. Ogden CL, Carroll MD, Curtin LR et al. (2010) Prevalence of high body mass index in US children and adolescents, 2007-2008. JAMA 303, 242-249.

2. Story M, Nanney MS \& Schwartz MB (2009) Schools and obesity prevention: creating school environments and policies to promote healthy eating and physical activity. Milbank Q 87, 71-100.

3. Resnicow K (1993) School-based obesity prevention. Population versus high-risk interventions. Ann N Y Acad Sci 699, 154-166.

4. Barlow SE (2007) Expert committee recommendations regarding the prevention, assessment, and treatment of child and adolescent overweight and obesity: summary report. Pediatrics 120, Suppl. 4, S164-S192.

5. Bullock SL, Craypo L, Clark SE et al. (2010) Food and beverage environment analysis and monitoring system: a reliability study in the school food and beverage environment. J Am Diet Assoc 110, 1084-1088.

6. Caballero B, Clay T, Davis SM et al. (2003) Pathways: a school-based, randomized controlled trial for the prevention of obesity in American Indian schoolchildren. $A m \mathrm{~J}$ Clin Nutr 78, 1030-1038.

7. Goldberg JP, Collins JJ, Folta SC et al. (2009) Retooling food service for early elementary school students in Somerville, Massachusetts: the Shape Up Somerville experience. Prev Chronic Dis 6, A103.

8. Lytle LA, Kubik MY, Perry C et al. (2006) Influencing healthful food choices in school and home environments: results from the TEENS study. Prev Med 43, 8-13.

9. Parker L \& Fox A (2001) The Peterborough Schools Nutrition Project: a multiple intervention programme to improve school-based eating in secondary schools. Public Health Nutr 4, 1221-1228.

10. Perry CL, Bishop DB, Taylor GL et al. (2004) A randomized school trial of environmental strategies to encourage fruit and vegetable consumption among children. Health Educ Behav 31, 65-76.
11. Tester JM, Yen IH \& Laraia B (2010) Mobile food vending and the after-school food environment. Am J Prev Med 38, $70-73$.

12. Kubik MY, Lytle LA, Hannan PJ et al. (2003) The association of the school food environment with dietary behaviors of young adolescents. Am J Public Health 93, 1168-1173.

13. Evans CE, Cleghorn CL, Greenwood DC et al. (2010) A comparison of British school meals and packed lunches from 1990 to 2007: meta-analysis by lunch type. Br J Nutr 104, 474-487.

14. Sanigorski AM, Bell AC, Kremer PJ et al. (2005) Lunchbox contents of Australian school children: room for improvement. Eur J Clin Nutr 59, 1310-1316.

15. Sallis JF, McKenzie TL, Conway TL et al. (2003) Environmental interventions for eating and physical activity: a randomized controlled trial in middle schools. Am J Prev Med 24, 209-217.

16. van der Horst K, Timperio A, Crawford D et al. (2008) The school food environment associations with adolescent soft drink and snack consumption. Am J Prev Med 35, 217-223.

17. Coleman KJ, Shordon M, Caparosa SL et al. (2012) The healthy options for nutrition environments in schools (Healthy ONES) group randomized trial: using implementation models to change nutrition policy and environments in low income schools. Int J Behav Nutr Phys Act 9, 80.

18. Herbert J \& Attridge C (1975) A guide for developers and users of observation systems and manuals. Am Educ Res J 12, $1-20$.

19. McKenzie TL, Marshall SJ, Sallis JF et al. (2000) Leisure-time physical activity in school environments: an observational study using SOPLAY. Prev Med 30, 70-77.

20. California Center for Public Health Advocacy (2011) SB 12 (Escutia): School Nutrition Standards - Summary. http:// www.publichealthadvocacy.org/PDFs/SB12Summary.pdf (accessed June 2011).

21. US Department of Agriculture (2004) HealthierUS School Challenge. http://www.fns.usda.gov/tn/healthierus/index.html (accessed June 2011).

22. Institute of Medicine of the National Academies, Committee on Nutrition Standards for Foods (2007) Nutrition Standards for Foods in Schools: Leading the Way Toward Healthier Youth. Washington DC: The National Academies Press.

23. Fox MK, Gordon A, Nogales R et al. (2009) Availability and consumption of competitive foods in US public schools. J Am Diet Assoc 109, 2 Suppl., S57-S66.

24. School Nutrition Association (2006) A Foundation for the Future II: Analysis of Local Wellness Policies from 140 School Districts in 49 States. Alexandria, VA: SNA; available at http://www.schoolnutrition.org/uploadedFiles/School_ Nutrition/102_ResourceCenter/RunningYourProgram/Local SchoolWellnessPolicies/RegionalLWPReport.doc

25. Ammerman AS, Ward DS, Benjamin SE et al. (2007) An intervention to promote healthy weight: Nutrition and Physical Activity Self-Assessment for Child Care (NAP SACC) theory and design. Prev Chronic Dis 4, A67.

26. Benjamin SE, Neelon B, Ball SC et al. (2007) Reliability and validity of a nutrition and physical activity environmental self-assessment for child care. Int J Behav Nutr Phys Act 4, 29.

27. Ward DS, Benjamin SE, Ammerman AS et al. (2008) Nutrition and physical activity in child care: results from an environmental intervention. Am J Prev Med 35, 352-356.

28. Glanz K, Sallis JF, Saelens BE et al. (2007) Nutrition Environment Measures Survey in stores (NEMS-S): development and evaluation. Am J Prev Med 32, 282-289.

29. Saelens BE, Glanz K, Sallis JF et al. (2007) Nutrition Environment Measures Study in restaurants (NEMS-R): development and evaluation. Am J Prev Med 32, 273-281. 
30. Piernas C \& Popkin MF (2010) Trends in snacking among US children. Health Aff (Millwood) 29, 398-404.

31. Field AE, Austin SB, Gillman MW et al. (2004) Snackfood intake does not predict weight change among children and adolescents. Int J Obes Relat Metab Disord 28, 1210-1216.

32. Hampl JS, Heaton CLB \& Taylor CA (2003) Snacking patterns influence energy and nutrient intakes but not body mass index. J Hum Nutr Diet 16, 3-11.
33. Nicklas TA, Morales M, Linares A et al. (2004) Children's meal patterns have changed over a 21-year period: the Bogalusa Heart Study. J Am Diet Assoc 104, 753-761.

34. Phillips SM, Bandini LG, Naumova EN et al. (2004) Energydense snack food intake in adolescence: longitudinal relationship to weight and fatness. Obes Res 12, 461-472.

35. Francis LA, Lee Y \& Birch LL (2003) Parental weight status and girls' television viewing, snacking, and body mass indexes. Obes Res 11, 143-151. 